\title{
A expressão "Tratamento Temático da Informação" em artigos de periódicos nacionais: análise da ocorrência e de suas variantes designativas
}

\section{The expression "Subject Representation" in Brazilian journal articles: an analysis of its occurrence and designative variations}

\author{
Lais Pereira de Oliveira ${ }^{1}$, Maria Cláudia Cabrini Grácio² ${ }^{2}$ Daniel Martínez-Ávila ${ }^{3}$ \\ 1 Universidade Estadual Paulista Júlio de Mesquita Filho - Unesp, Marília, SP, Brasil e Universidade Federal de Goiás - UFG, Goiânia, GO, Brasil. ORCID: \\ http://orcid.org/0000-0001-9092-4204 \\ 2 Universidade Estadual Paulista Júlio de Mesquita Filho - Unesp, Marília, SP, Brasil. ORCID: https://orcid.org/0000-0002-8003-0386 \\ 3 Universidad Carlos III de Madrid - UC3M, Madri, Espanha e Universidade Estadual Paulista Júlio de Mesquita Filho - Unesp, Marília, SP, Brasil. ORCID: \\ https://orcid.org/0000-0003-2236-553X
}

Autor para correspondência/Mail to: Lais Pereira de Oliveira, laispereira2@yahoo.com.br

Recebido/Submitted: 5 de Julho de 2020; Aceito/Approved: 3 de setembro de 2020

Copyright (c) 2020 Oliveira, Grácio \& Martínez-Ávila. Todo o conteúdo da Revista (incluindo-se instruções, política editorial e modelos) está sob uma licença Creative Commons Atribuição-NãoComercial-Compartilhalgual 3.0 Não Adaptada. Ao serem publicados por esta Revista, os artigos são de livre uso em ambientes educacionais, de pesquisa e não comerciais, com atribuição de autoria obrigatória. Mais informações em http://revistas.ufpr.br/atoz/about/submissions\#copyrightNotice.

\begin{abstract}
Resumo
Introdução: Aborda o Tratamento Temático da Informação em sua perspectiva teórica, entendido enquanto dimensão fundamental em Organização da Informação, detida à representação de atributos relativos ao conteúdo, essenciais para viabilizar a busca e recuperação por assunto. Objetiva analisar a ocorrência da expressão "Tratamento Temático da Informação" e de suas variantes designativas em artigos de periódicos brasileiros da Ciência da Informação, versados no tema, como forma de aclarar o assunto em sua perspectiva terminológica e perscrutar seu lastro teórico na literatura. Método: Constitui estudo descritivo de natureza quantitativa, na forma de pesquisa bibliográfica, com aplicação da bibliometria sobre artigos de periódicos obtidos na Base de Dados Referencial de Artigos de Periódicos em Ciência da Informação, mediante busca pela expressão "Tratamento Temático da Informação". Congrega um corpus de 23 artigos, analisados individualmente com apoio do registro dos dados via Planilha do Excel e geração de gráficos e tabelas. Resultados: Demonstra a recorrência do termo "Tratamento Temático da Informação" nos artigos que versam sobre o tema, com predomínio da expressão na revisão de literatura. Insurge também, no título, no resumo e nas palavras-chave. Evidencia, entre as variantes designativas, as nomenclaturas "descrição" e "representação temática". Conclusão: O Tratamento Temático da Informação vem se afirmando na literatura brasileira, na medida em que se estabelece como designação padrão da dimensão temático-organizativa nas publicações desse entorno.
\end{abstract}

Palavras-chave: Organização da Informação; Tratamento Temático da Informação; Produção científica - Brasil; Bibliometria; BRAPCI

\begin{abstract}
Introduction: It deals with subject representation in its theoretical perspective, understood as a fundamental dimension in information organization, focused on the representation of attributes related to the content that are essential to enable the search and retrieval by subject. It aims to analyze the occurrence of the expression "subject representation" and its designative variations in articles in Brazilian journals on Information Science, as a way to clarify the subject in its terminological perspective and to examine its theoretical basis in literature. Method: It is a descriptive study of a quantitative nature, in the form of bibliographic research and the application of bibliometrics on journal articles retrieved from the "Base de Dados Referencial de Artigos de Periódicos em Ciência da Informação" (BRAPCl database) using the term "Tratamento Temático da Informação" (Portuguese term for "subject representation"). It comprises a corpus of 23 articles that were analyzed individually using Excel spreadsheets and the generation of graphs and tables. Results: It shows the recurrence of the term "subject representation" in the articles on the topic, with a predominance of the expression in the literature review. It also appears in the title, abstract, and keywords. It reveals the designative variants in Portuguese. Conclusions: It concludes that subject representation has been consolidated in the Brazilian literature, insofar as it is established as a standard designation for the subject representation dimension in publications.
\end{abstract}

Keywords: Information organization; Subject representation; Scientific production - Brazil; Bibliometrics; BRAPCI

\section{INTRODUÇÃO}

A dedicação sobre o assunto dos documentos é uma questão peculiar à área de Biblioteconomia e Ciência da Informação, na qual seu conceito vem sendo examinado e, tradicionalmente, procedimentos de classificação, indexação e busca por assunto são levados a cabo (Hjørland, 2017).

Ademais, esforços significativos foram feitos, sobretudo nos séculos XIX e XX, para facilitar a abordagem do assunto, que remonta a Bliss, assim como ao trabalho do Classification Research Group e a teóricos como Shera. Outro importante autor nessa delimitação da instância de assunto foi A. C. Foskett, cuja obra The subject approach to information introduziu a divisão entre as abordagens descritiva e temática (Hider, 2020). 
Estabelece-se, pois, uma dimensão aplicada de caráter analítico, mas sustentada em nível teórico-conceitual, que se presta à representação dos assuntos mediante atributos dessa ordem, tanto quanto à constituição de instrumentos voltados para esse fim. Tratamento Temático da Informação (TTI) é uma das formas de designação desse conjunto de conhecimentos.

As variações na expressão "tratamento temático da informação", que caracteriza uma dimensão da organização da informação (OI) mediadora entre documentos e usuários (Braz \& de Carvalho, 2017), muito dizem sobre a forma como tem sido enxergada na Ciência da Informação. Afinal, os autores escolhem os termos técnicos a serem empregados em seus artigos científicos (Whittaker, 1989).

Busca-se, no TTI, por meio de um conjunto de processos, produtos e instrumentos (Oliveira \& Martínez-Ávila, 2019), identificar, processar e disponibilizar o conteúdo informacional (Pando \& Guimarães, 2006). Essa vertente da OI engloba, portanto, compreender e extrair assuntos (Vieira, Oliveira, \& Cunha, 2017), auxiliando significativamente na recuperação da informação (Catarino, Cervantes, \& Andrade, 2015).

Enquanto dimensão organizativa de representação do conteúdo contido nos documentos, o TTI corporifica-se como uma área desafiadora (Sousa, 2013). Ainda assim, atende à busca e à recuperação por assunto, sendo fundamental na cadeia documental. Apesar disso, tem sido relegado na literatura se comparado ao tratamento descritivo, tradicionalmente mais abordado e enfatizado em seu caráter individual.

Logo, mapear e caracterizar a produção científica nacional sobre o termo TTI e seus correlatos pode afigurar seu desenvolvimento e consolidação, sobretudo em razão da sua falta de sedimentação conceitual (Guimarães \& Sales, 2010). Ademais, considera-se que investigar o tratamento temático da informação é uma forma de buscar consolidá-lo teórica e aplicadamente (Oliveira, Grácio, \& Martínez-Ávila, 2020), permitindo enxergá-lo distintivamente, de modo particular e individualizado do trato descritivo.

É comum a condução conjunta do trato descritivo e temático (Oliveira et al., 2020). A designação da descrição de conteúdo deu-se, de fato, em analogia com a operação de descrição bibliográfica Guinchat e Menou (1994). Contudo, é importante dimensionar devidamente cada instância, compreendendo a abrangência do TTI (Bräscher \& Guimarães, 2018).

Esse é o propósito da presente pesquisa. De forma análoga, no mesmo domínio da organização do conhecimento, Hjørland (2012) utilizou técnicas bibliométricas para estudar e comparar o uso e as características de diversas denominações do campo. Há que se considerar, ainda, a importância do ato de nomear, presente na própria ação de representação de assunto (Olson, 2002), e que aqui é também buscada.

Este estudo objetiva, pois, analisar a ocorrência da expressão "tratamento temático da informação" e de suas variantes designativas em artigos de periódicos brasileiros da Ciência da Informação, versados no tema, como forma de aclarar o assunto em sua perspectiva terminológica e perscrutar seu lastro teórico na literatura. Parte-se do pressuposto que a produção científica nacional sobre o TTI congrega distintas nomenclaturas, dificultando a formação de uma identidade nominal padrão e verdadeiramente indicativa do assunto.

O problema de pesquisa versa, portanto, sobre a diversidade de nomenclaturas em tratamento temático da informação, tal como expresso na designação das produções científicas. Intenta, ainda, sobre a controversa distinção nominativa pelo próprio autor do artigo, ao incorrer em variantes no decorrer de seu texto. Aspecto esse que acaba por incidir no desenvolvimento teórico do TTI, trazendo implicações à sua sustentação conceitual.

Nessa medida, avizinha-se da problemática expressão do tema TTI, para o qual não há uma correspondência clara com a expressão em inglês (Gracioso, Martínez-Ávila, \& Simões, 2019) e, mesmo em âmbito nacional, reflete inúmeras outras designações. Análise documentária, análise temática, análise de assunto e descrição de conteúdo são algumas delas, além da própria denominação enquanto tratamento temático da informação (Café \& Sales, 2010).

Vislumbra-se, pois, a contribuição para a literatura produzida em TTI tanto quanto para a vertente aplicada consubstanciada no trabalho técnico-intelectual em unidades de informação.

\section{TRATAMENTO TEMÁTICO DA INFORMAÇÃO}

A constante produção literária gerou a necessidade de organizar o conhecimento em acervos (Silva \& Silva, 2012). O interesse humano, centrado no conteúdo dos acervos, está presente desde o século XV (Araújo, 2020). A mudança paradigmática de ênfase no conteúdo e não no documento em si, por sua vez, acontece a partir do surgimento da Ciência da Informação (Robredo, 2004), enquanto a necessidade pragmática de trato documental levou ao desenvolvimento do tratamento temático da informação (Guimarães, 2008).

O crescente número de documentos, formando acervos, passa a exigir a representação lógica dos assuntos (Souza, 2007), incitando assim, o desenvolvimento do TTI em nível aplicado. Esse começa a aparecer também, de forma pontual, na própria formação acadêmica do bibliotecário, a partir de um conjunto de disciplinas base tangenciadas com aquelas dedicadas ao tratamento descritivo, assegurando, portanto, a ação prática-laboral 
nesse âmbito. Afinal, práticas e técnicas, como observa Danuello (2007), foram desenvolvidas desde a criação dos cursos de Biblioteconomia, com vistas à organização dos materiais e ao acesso rápido e eficiente às suas informações.

Além disso, uma dimensão teórica própria vai ganhando forma a partir do momento em que se percebe a importância da investigação do eixo de assunto, ainda que de forma um tanto tardia. Guimarães (2008) sinaliza para a preocupação, a partir dos anos de 1950, com o desenvolvimento de bases científicas para o fazer do TTI. A esse respeito, Albrechtsen (1993) explicita que a comunidade de pesquisadores despertou após anos do sono mágico para, então, ter o assunto como tema de pesquisa. Foskett foi, a propósito, o responsável pela veiculação "primeva"do TTI na literatura (Café \& Sales, 2010).

Entendido como macroprocesso que evidencia os atributos de assunto do documento (Oliveira et al., 2020), o tratamento temático da informação ocupa posição nuclear na Ciência da Informação (Guimarães, 2008), por envolver a análise e a representação do conteúdo (Danuello, 2007). Propicia, com isso, a interlocução da produção e do uso da informação Guimarâes, Ferreira, e Freitas (2011).

A representação dos conteúdos é buscada a partir dos processos técnicos de classificação, indexação e elaboração de resumos (Baptista, 1994). Corporifica-se, assim, a dimensão de tratamento temático da informação, impulsionada desde a década de 1970 com a referida denominação (Guimarães, 2008).

O tratamento temático da informação aborda, dessa forma, o assunto presente no documento, sendo crucial uma descrição do conteúdo que propicie uma busca e recuperação eficaz (Sousa \& Fujita, 2013). Há esforços para definição do termo, sobretudo a partir de Guimarães (2008) (Gracioso et al., 2019). Falta, contudo, concordância terminológica nos processos da organização do conhecimento (Bräscher \& Guimarães, 2018) e, assim, no próprio TTI. A representação da informação nas perspectivas física e temática foi, afinal, observada historicamente (Vieira, Bräscher, Silva, \& Karpinski, 2020), mas o tratamento temático da informação tem recebido tratamento distinto na literatura (Oliveira et al., 2020).

Guimarães (2008, p.79) explica que "o desenvolvimento do TTI ao longo da história foi, pouco a pouco, sendo permeado por distintas concepções". Correntes teóricas distintas levam, pois, à sua variação terminológica (Oliveira \& Martínez-Ávila, 2019). São elas: catalogação de assunto, indexação e análise documental. As duas primeiras estão centradas nos instrumentos e produtos do TTI, enquanto que a última se volta aos procedimentos envolvidos em seu entorno (Guimarâes et al., 2011), implicando no efetivo entendimento do significado dos documentos (Dal'Evedove \& Fujita, 2013).

Dessa forma, a abordagem da catalogação de assunto decorre dos princípios de catalogação alfabética de Cutter e da tradição de cabeçalhos de assunto da Library of Congress. Tem forte influência da Escola de Chicago e volta-se, de modo direto, à atividade profissional em bibliotecas. A indexação foca nos índices como produto, abrangendo centros de documentação especializados e o universo editorial. É influenciada pelos trabalhos do Classification Research Group. A análise documental pressupõe aportes interdisciplinares da Linguística, da Lógica e da Terminologia para decomposição e representação do conteúdo informacional, com sustentação em Coyaud e Gardin (Guimarães, 2008).

O tratamento temático tem, portanto, a construção do seu referencial teórico-metodológico embasado nessas correntes teóricas (Guimarães, 2008). A vertente anglo-saxônica teve maior representatividade na literatura internacional, por meio das abordagens de matriz norte-americana e inglesa, respectivamente corporificadas na catalogação de assunto e na indexação. Já a análise documental influiu nos trabalhos de pesquisadores da Espanha e, no Brasil, encontrou eco em teóricos como Smit, Cintra, Kobashi, Lara e Tálamo (Guimarâes et al., 2011).

Reis (2015) fala da influência dos estudos sobre análise documentária de orientação francesa no Brasil. O Grupo Temma, da Universidade de São Paulo, embasou-se nessa perspectiva. Fundado em 1986, teve a análise documentária — assim formalmente subscrita - como linha de pesquisa a partir de iniciativa de Johanna Wilhelmina Smit (Lara, 2011).

Nessa medida, variantes terminológicas em TTI tiveram lugar na literatura brasileira de Biblioteconomia e Ciência da Informação, seja por influência das correntes teóricas que marcadamente a constituíram, seja pelas concepções internas relativas ao desenho formativo nas graduações de Biblioteconomia e nos programas de pós-graduação em Ciência da Informação, ou mesmo pelo lastro teórico consubstanciado em eventos científicos e, inclusive, junto aos grupos de pesquisa como o supramencionado.

Há que se atentar, ainda, que o processo de tratamento temático da informação se altera, a depender do contexto profissional (Dal'Evedove, 2014). Desse modo, também em nível aplicado as concepções nesse entorno se modificam.

Fato é que, ainda que sob outras designações, o TTI objetiva fundamentalmente a extração ou associação dos assuntos mais representativos do conteúdo, para sua identificação particular (Rabelo \& Bentes, 2019), referindo-se 
à análise, descrição e representação do conteúdo, de forma específica (Guimarâes et al., 2011). Seu entorno, contudo, precisa ser mais explorado, principalmente em âmbito teórico.

\section{METODOLOGIA}

Tem-se uma pesquisa descritiva de natureza quantitativa e, bibliográfica, direcionada para teor analítico com aplicação da bibliometria sobre conjuntos de informação textual, seu material de base (Robredo \& Vilan Filho, 2010). Emprega-se assim, a perspectiva metodológica dos estudos métricos (Oliveira \& Gracio, 2011).

A partir de prospecção na Base de Dados Referencial de Artigos de Periódicos em Ciência da Informação (BRAPCI), no ano de 2020, constituiu-se corpus de pesquisa formado por artigos de periódicos nacionais dessa área sobre TTI. Essa expressão foi usada em sua forma completa, considerando a busca conjunta nos campos de título, palavras-chave e resumo da base, no período de 1972 até 2019.

Logo, realizou-se busca simples na BRAPCI pelo termo "tratamento temático da informação". Isso por conta de o foco central da pesquisa ser sobre o TTI assim expresso, ainda que se cerque de outras formas de designação derivadas das diversas correntes presentes na literatura. Outrossim, tencionou-se analisar as variantes designativas para o assunto, presentes nos artigos recuperados pela expressão "tratamento temático da informação", e não, prospectá-las na base de dados que foi fonte de pesquisa.

Desse modo, a investigação envolveu uma etapa inicial de busca dirigida do tema na literatura, pelo termo TTI, tendo como fonte a BRAPCI. Em um segundo momento, perpassou também pela seleção individualizada dos registros retornados, para verificação da aderência temática ao assunto. E, finalmente, englobou teor analítico sobre os artigos componentes do corpus de pesquisa, para os fins propostos de acordo com o objetivo do estudo.

Logo, dos 55 artigos retornados na busca supramencionada, apenas 23 compuseram o corpus de pesquisa (Quadro 1), por versarem sobre o tema analisado. O recorte foi feito após uma limpeza manual dos registros pela análise de conteúdo do título, do resumo, das palavras-chave e, em alguns casos, também da introdução.

Analisou-se individualmente artigo por artigo, mediante visualização de suas versões em pdf. As ocorrências da expressão "tratamento temático da informação" foram, então, contabilizadas ao longo do texto, identificando as partes em que se apresentava. Para tanto, recorreu-se à busca intratextual do termo, via recurso de localização no arquivo.

Cada ocorrência da expressão foi contabilizada e registrada, juntamente com a identificação da seção em que surgia. O mesmo procedimento foi feito na observância das variantes designativas do TTI no texto, no intuito de reconhecer todos os termos correlatos ao tratamento temático da informação, expressos pelo autor da publicação. 
Danuello e Guimarães (2005). Produção científica docente em tratamento temático da informação nos cursos de Biblioteconomia do Mercosul: uma análise preliminar.

Guimarães (2008). A dimensão teórica do tratamento temático da informação e suas interlocuções com o universo científico da International Society for Knowledge Organization (ISKO).

Guimarães e Sales (2010). Análise documental: concepções do universo acadêmico brasileiro em Ciência da Informação.

Guimarães, Sales e Grácio (2012). A dimensão interdisciplinar da análise documental nos contextos brasileiro e espanhol no âmbito da organização do conhecimento.

Kochani, Boccato e Rubi (2012). Política de indexação para clippings: otimização do tratamento temático em coordenadorias de comunicação social brasileiras.

Dal'Evedove e Fujita (2013). Estudo sociocultural da comunidade discursiva do tratamento temático da informação em bibliotecas universitárias.

Dias e Cervantes (2013). Tratamento temático da informação em periódicos científicos eletrônicos na Biblioteconomia e Ciência da Informação.

Souza (2013). Representação temática da informação documentária e sua contextualização em biblioteca.

Souza e Fujita (2013). A classificação bibliográfica no contexto do tratamento temático da informação: um estudo com protocolo verbal individual em bibliotecas do Instituto Federal de Educação, Ciência e Tecnologia (IF's).

Rodrigues e Cervantes (2014). Organização e representação do conhecimento por meio de mapas conceituais.

Rodrigues e Cervantes (2015). Análise de assunto e mapas conceituais: semelhanças nos processos.

Machado e Albuquerque (2016). A representação temática da xilogravura: o processo de indexação da coleção Paulo Menten.

Medeiros, Vital e Bräscher (2016). Tratamento temático da informação em documentos arquivísticos: estudo dos anais da ISKO e do GT2 do ENANCIB.

Braz e Carvalho (2017). Práticas em tratamento temático da informação: interfaces de ensino e aprendizagem.

Cervantes, Suenaga e Rodrigues (2017). Os conceitos no tratamento da informação arquivística: unidade basilar para a compreensão do conteúdo documental.

Redigolo e Silva (2017). A representação temática como mediadora implícita da informação em bibliotecas universitárias.

Sales e Guimarães (2017). O método analítico-sintético de Julius Kaiser: um pioneirismo para o tratamento temático da informação.

Vieira, Oliveira e Cunha (2017). Incursões sobre o tratamento temático da informação: estudo da política de indexação em bibliotecas universitárias goianas.

Bräsher e Guimarães (2018). Tratamento temático da informação (TTI): influência dos paradigmas físico, cognitivo e social em artigos de revisão de literatura no período de 1966-1995.

Linden e Bräscher (2018). O tratamento temático da informação em instrumentos normativos de descrição arquivística.

Carvalho e Almeida (2019). Coleções de multimeios: reflexões sobre o tratamento temático da informação a partir do conceito de tradução intersemiótica.

Oliveira e Martínez-Ávila (2019). Tratamento temático da informação: análise sobre abordagens e enfoques em artigos científicos da área de Ciência da Informação.

Sundström, Moraes e Albuquerque (2019). Filme de ficção para a Ciência da Informação: um estudo sobre as abordagens de organização e representação temática.

Quadro 1. Artigos sobre tratamento temático da informação.

Fonte: dados da pesquisa (2020)

O registro dos dados assim como a construção das tabelas descritivas e dos gráficos foram realizados no software Excel.

\section{ANÁLISE E INTERPRETAÇÃO DOS DADOS}

A Figura 1 apresenta a distribuição temporal dos 23 artigos analisados, de acordo com a denominação do termo em seus títulos. Um total de 13 trabalhos traz a expressão TTI de forma completa já no título. Outrossim, predominam na nomeação das produções as expressões "tratamento temático da informação", apenas "tratamento temático" ou ainda, "tratamento da informação". As duas últimas com apenas uma ocorrência cada. Juntos, os três modos de designação alcançam mais da metade das publicações no tema. 


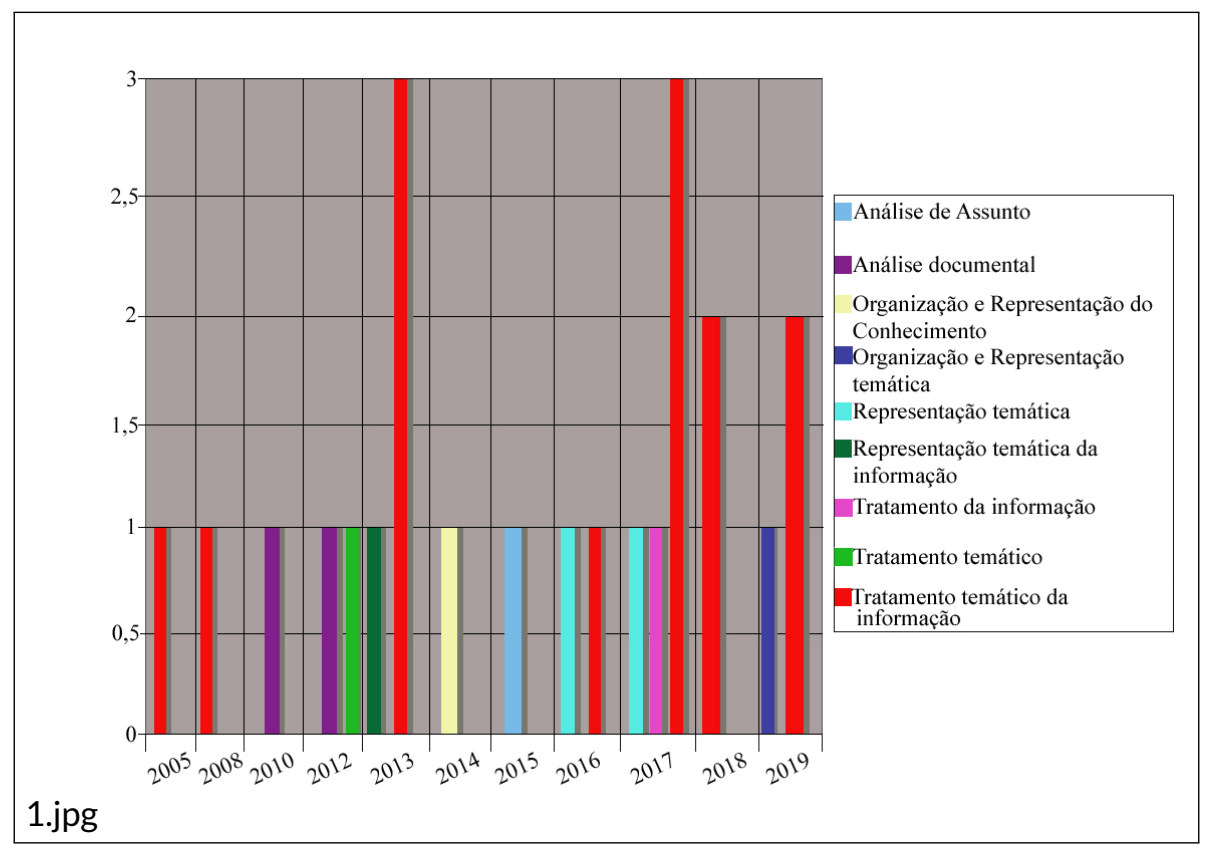

Figura 1. Tratamento temático da informação no título dos artigos. Fonte: dados da pesquisa (2020)

Reverberam assim, nos títulos dos artigos, variações da própria forma TTI, concentradas principalmente nos anos de 2016, 2017, 2018 e 2019. Há ainda, outras palavras na denominação das produções, trazendo os termos "análise", "organização" e "representação" na composição. Mas, estas aparecem em menor número, a partir do ano de 2010.

Em certa medida, tais dados demonstram a falta de sedimentação conceitual apontada por Guimarães e Sales (2010), já que os pesquisadores intitulam os artigos sobre o assunto de distintas formas. A escolha dos termos técnicos pelos autores das publicações (Whittaker, 1989) tem, portanto, sido bastante diversificada, por não haver uma linha nominativa comum já na parte inicial do texto, que traz a denominação do trabalho.

A Tabela 1 apresenta a ocorrência do termo TTI nos resumos de cada artigo objeto de análise, em que se observa que somente 4 dos 23 trabalhos não o mencionam nessa parte do texto.

Ao aparecer no resumo, a nomenclatura "tratamento temático da informação" acaba por ser enfatizada pelo autor do artigo, por ser este um item em que se tem a indicação dos pontos, ideias, premissas e fatos principais do texto original (Gonçalves, 2008; Lunardelli, 2017). Ademais, como o próprio TTI busca identificar, processar e disponibilizar conteúdo informacional (Pando \& Guimarães, 2006), é extremamente significativo que as publicações a ele voltadas ensejem esse caráter suficientemente informativo no resumo, evidenciando-o de forma clara para o leitor.

Observa-se ainda, que a ocorrência do termo TTI é mais frequente na introdução do resumo (12 das 36), o que evidencia a preocupação do autor em explicá-lo e contextualizá-lo para o leitor. Em Guimarães, Sales e Grácio, aliás, aparece em duas ocasiões distintas nessa parte. 


\begin{tabular}{|c|c|c|c|c|}
\hline Ano & $\begin{array}{c}\text { Total de } \\
\text { artigos com } \\
\text { o termo TTI }\end{array}$ & Autoria & $\begin{array}{c}\text { Ocorrências } \\
\text { no resumo } \\
\text { do artigo }\end{array}$ & Parte do resumo \\
\hline 2005 & 1 & Danuello e Guimarães & 3 & $\begin{array}{l}\text { Introdução (1), Metodologia (1) } \\
\text { e Resultados (1) }\end{array}$ \\
\hline 2008 & 1 & Guimarães & 1 & Introdução (1) \\
\hline 2010 & 1 & Guimarães e Sales & 1 & Introdução (1) \\
\hline \multirow{2}{*}{2012} & \multirow{2}{*}{2} & Guimarães, Sales e Grácio & 2 & Introdução (2) \\
\hline & & Kochani, Boccato e Rubi & 1 & Introdução (1) \\
\hline \multirow{4}{*}{2013} & \multirow{4}{*}{2} & Dal'Evedove e Fujita & 3 & $\begin{array}{l}\text { Introdução (1), Objetivo (1) } \\
\text { e Resultados (1) }\end{array}$ \\
\hline & & Dias e Cervantes & - & - \\
\hline & & Souza & - & - \\
\hline & & Souza e Fujita & 1 & Objetivo (1) \\
\hline 2014 & 1 & Rodrigues e Cervantes & 1 & Conclusão (1) \\
\hline 2015 & 1 & Rodrigues e Cervantes & 2 & Introdução (1) e Objetivo (1) \\
\hline \multirow{2}{*}{2016} & \multirow{2}{*}{2} & Machado e Albuquerque & 1 & Objetivo (1) \\
\hline & & Medeiros, Vital e Bräsher & 1 & Objetivo (1) \\
\hline \multirow{5}{*}{2017} & \multirow{5}{*}{4} & Braz e Carvalho & 2 & Introdução (1) e Objetivo (1) \\
\hline & & Cervantes, Suenaga e Rodrigues & 3 & Introdução (1) e Resultados (2) \\
\hline & & Redigolo e Silva & 4 & $\begin{array}{l}\text { Objetivo (1), Metodologia (2) } \\
\text { e Resultados (1) }\end{array}$ \\
\hline & & Sales e Guimarães & 1 & Metodologia (1) \\
\hline & & Vieira, Oliveira e Cunha & - & - \\
\hline \multirow{2}{*}{2018} & \multirow{2}{*}{2} & Bräsher e Guimarães & 1 & Objetivo (1) \\
\hline & & Linden e Bräsher & 4 & $\begin{array}{l}\text { Objetivo (1), Metodologia (1) } \\
\text { e Conclusão (2) }\end{array}$ \\
\hline \multirow{3}{*}{2019} & \multirow{3}{*}{2} & Carvalho e Almeida & 2 & Introdução (1) e Conclusão (1) \\
\hline & & Oliveira e Martínez-Ávila & 2 & Introdução (1) e Objetivo (1) \\
\hline & & Sundström, Moraes e Albuquerque & - & - \\
\hline Total & 19 & & 36 & \\
\hline
\end{tabular}

Tabela 1. Tratamento temático da informação no resumo dos artigos.

Fonte: dados da pesquisa (2020)

Ademais, a alta ocorrência da expressão também na descrição do objetivo no resumo (10 das 36), mostra a relevância do tema na produção, na medida em que direciona o estudo demonstrando sua finalidade. Sua sinalização na metodologia dos resumos transparece a preocupação de descrever o TTI procedimentalmente. Já nos casos em que surge nos resultados e na conclusão, reforça o aspecto de análise e de constatação sobre o tema.

A Tabela 2 apresenta o resultado da presença do termo TTI entre as palavras-chave dos artigos, observando-se sua ausência em uma minoria dos textos, os quais se encontram entre aqueles que utilizaram poucas palavras-chave (entre 3 e 4). No caso das publicações que utilizam, trata-se de um sinal da repercussão do assunto no artigo, também configurado como um termo representativo, em alguns casos de forma complementar ao uso que foi feito já no resumo. 


\begin{tabular}{|c|c|c|c|}
\hline Ano & Autoria & $\begin{array}{c}\text { Presença do TTI nas palavras- } \\
\text { chave }\end{array}$ & Total de palavras-chave \\
\hline 2005 & Danuello e Guimarães & $\operatorname{sim}$ & 4 \\
\hline 2008 & Guimarães & $\operatorname{sim}$ & 6 \\
\hline 2010 & Guimarães e Sales & $\operatorname{sim}$ & 6 \\
\hline \multirow{2}{*}{2012} & Guimarães, Sales e Grácio & $\operatorname{sim}$ & 3 \\
\hline & Kochani, Boccato e Rubi & $\operatorname{sim}$ & 4 \\
\hline \multirow{4}{*}{2013} & Dal' Evedove e Fujita & sim & 5 \\
\hline & Dias e Cervantes & não & 4 \\
\hline & Souza & não & 4 \\
\hline & Souza e Fujita & sim (termo pré-coordenado) & 3 \\
\hline 2014 & Rodrigues e Cervantes & $\operatorname{sim}$ & 4 \\
\hline 2015 & Rodrigues e Cervantes & $\operatorname{sim}$ & 3 \\
\hline \multirow{2}{*}{2016} & Machado e Albuquerque & não & 4 \\
\hline & Medeiros, Vital e Bräsher & sim & 3 \\
\hline \multirow{5}{*}{2017} & Braz e Carvalho & $\operatorname{sim}$ & 3 \\
\hline & Cervantes, Suenaga e Rodrigues & $\operatorname{sim}$ & 5 \\
\hline & Redigolo e Silva & sim & 3 \\
\hline & Sales e Guimarães & $\operatorname{sim}$ & 4 \\
\hline & Vieira, Oliveira e Cunha & não & 3 \\
\hline \multirow{2}{*}{2018} & Bräsher e Guimarães & $\operatorname{sim}$ & 4 \\
\hline & Linden e Bräsher & sim & 4 \\
\hline \multirow{3}{*}{2019} & Carvalho e Almeida & $\operatorname{sim}$ & 5 \\
\hline & Oliveira e Martínez-Ávila & não & 4 \\
\hline & Sundström, Moraes e Albuquerque & sim & 5 \\
\hline Total & & & 93 \\
\hline
\end{tabular}

Tabela 2. Tratamento temático da informação nas palavras-chave dos artigos. Fonte: dados da pesquisa (2020)

Comparando as tabelas 1 e 2, percebe-se que os mesmos autores que não utilizaram o termo TTI no resumo Dias e Cervantes (em 2013), Sousa (2013) e Vieira, Oliveira e Cunha (em 2017) — também não o fizeram nas palavras-chave. Salientam-se as exceções Machado e Albuquerque (em 2016) e Oliveira e Martínez-Ávila (em 2019), que empregaram o termo no resumo, mas não nas palavras-chave, ao passo que Sundström, Moraes e Albuquerque (em 2019) somente o fizeram nas palavras-chave.

Logo, dos 13 artigos em que se constatou a ocorrência da expressão TTI em sua forma completa no título, observou-se que 10 também a trazem simultaneamente no resumo e nas palavras-chave. São eles: Danuello e Guimarães; Guimarães; Dal'Evedove e Fujita; Sousa e Fujita; Medeiros, Vital e Bräscher; Braz e Carvalho; Sales e Guimarães; Bräscher e Guimarães; Linden e Bräscher; e Carvalho e Almeida. São produções que empregam o termo de forma consecutiva e reiterada nessas partes que abrem o artigo. A Figura 2 expõe essa correlação e também os trabalhos com ocorrências individuais do TTI no título, no resumo e nas palavras-chave. 


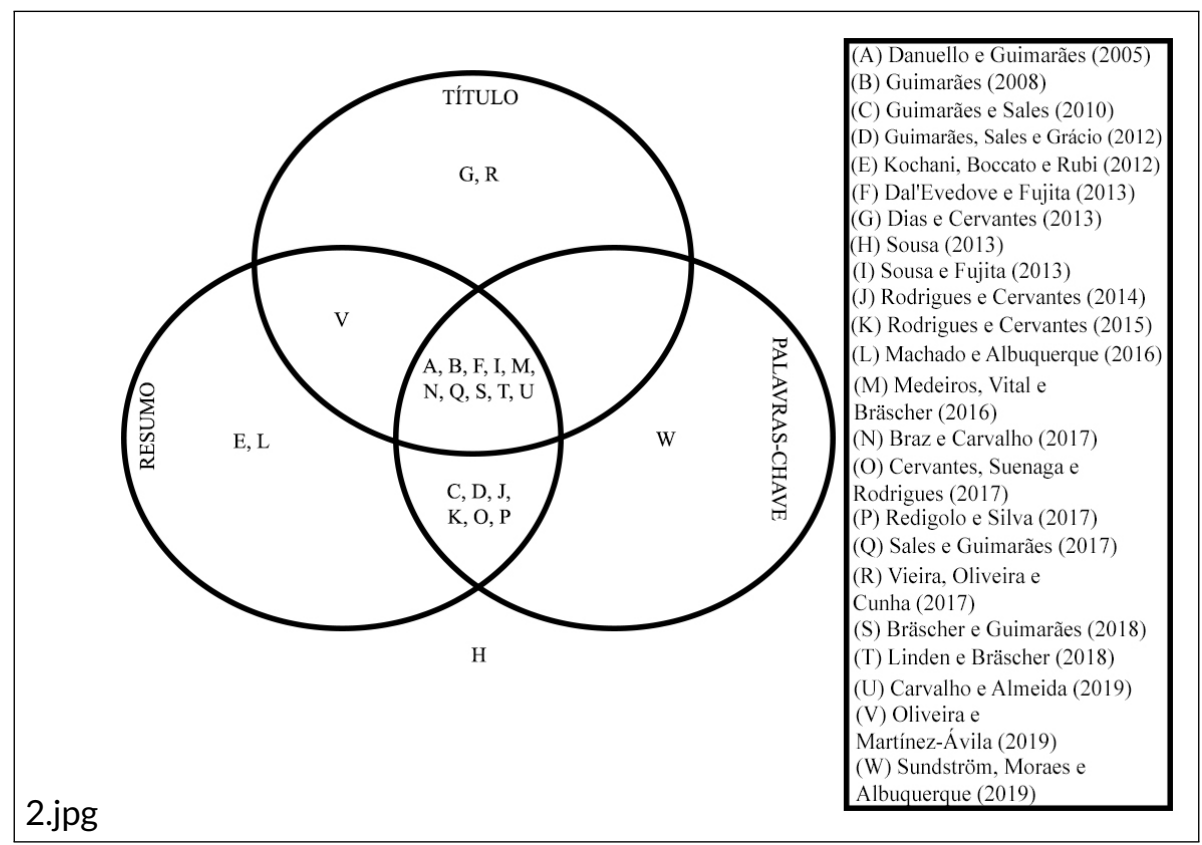

Figura 2. Mapa da ocorrência da expressão TTI no título, no resumo e nas palavras-chave. Fonte: elaboração própria (2020)

A Tabela 3 apresenta a ocorrência do termo TTI no texto dos artigos, desconsiderando título, resumo e palavraschave - analisados separadamente - assim como títulos das seções, notas de rodapé e referências, em que se observa um total de 172 ocorrências no corpus analisado, com uma média de 7 por artigo. Além disso, a intensidade da ocorrência da expressão nas publicações apresenta uma alta amplitude, ao variar entre 1 e 44 ocorrências.

A recorrência da expressão no texto se dá significativamente no item revisão de literatura, com um total de 60 ocorrências. Marcadamente, introdução e resultados também trazem o TTI grande número de vezes, respectivamente em 42 e 37 ocasiões. Em menor quantidade estão metodologia com 15 e conclusão com 18 ocorrências.

Na medida em que o tratamento temático da informação insurge no texto dos artigos sobre o referido tema, recuperados na BRAPCI, reforça sua importância na designação de um eixo fundamental em OI, que é o que se volta ao teor das informações contidas em um documento. Inclusive por já ter figurado no título e em alguns casos também no resumo e nas palavras-chave das publicações. Marcadamente, portanto, vai permeando o artigo em pontos distintos. 


\begin{tabular}{|c|c|c|c|}
\hline Ano & Autoria & Ocorrências & Parte do texto \\
\hline 2005 & Danuello e Guimarães & 1 & Introdução (1) \\
\hline 2008 & Guimarães & 2 & Introdução (1) e Conclusão \\
\hline 2010 & Guimarães e Sales & 7 & $\begin{array}{l}\text { Introdução (2), Revisão de literatura (3), } \\
\text { Metodologia (1), Resultados (1) }\end{array}$ \\
\hline \multirow[t]{2}{*}{2012} & Guimarães, Sales e Grácio & 9 & $\begin{array}{l}\text { Introdução (2), Revisão de literatura (5) e } \\
\text { Resultados (2) }\end{array}$ \\
\hline & Kochani, Boccato e Rubi & 4 & Revisão de literatura (3) e Resultados (1) \\
\hline \multirow{4}{*}{2013} & Dal'Evedove e Fujita & 44 & $\begin{array}{l}\text { Introdução (6), Revisão de literatura (11), } \\
\text { Metodologia (3), Resultados (20) e Conclusão (4) }\end{array}$ \\
\hline & Dias e Cervantes & - & - \\
\hline & Souza & 1 & Revisão de literatura (1) \\
\hline & Souza e Fujita & 3 & $\begin{array}{l}\text { Revisão de literatura (1), Metodologia (1) e } \\
\text { Conclusão (1) }\end{array}$ \\
\hline 2014 & Rodrigues e Cervantes & 1 & Introdução (1) \\
\hline 2015 & Rodrigues e Cervantes & 6 & $\begin{array}{l}\text { Introdução (3), Revisão de literatura (1), } \\
\text { Metodologia (1) e Resultados (1) }\end{array}$ \\
\hline \multirow{2}{*}{2016} & Machado e Albuquerque & 4 & Introdução (1) e Revisão de literatura (3) \\
\hline & Medeiros, Vital e Bräsher & 10 & $\begin{array}{l}\text { Introdução (1), Revisão de literatura (2), } \\
\text { Metodologia (2), Resultados (4) e Conclusão (1) }\end{array}$ \\
\hline \multirow{5}{*}{2017} & Braz e Carvalho & 7 & $\begin{array}{l}\text { Introdução (2), Revisão de literatura (4) e } \\
\text { Resultados (1) }\end{array}$ \\
\hline & Cervantes, Suenaga e Rodrigues & 2 & Revisão de literatura (2) \\
\hline & Redigolo e Silva & 15 & $\begin{array}{l}\text { Introdução (9), Revisão de literatura (8), } \\
\text { Metodologia (3) e Conclusão(2) }\end{array}$ \\
\hline & Sales e Guimarães & 15 & $\begin{array}{l}\text { Introdução (9), Metodologia (1), Resultados (3) e } \\
\text { Conclusão (2) }\end{array}$ \\
\hline & Vieira, Oliveira e Cunha & 6 & $\begin{array}{l}\text { Introdução (1), Revisão de literatura (3), } \\
\text { Resultados (1) e Conclusão (1) }\end{array}$ \\
\hline \multirow[t]{2}{*}{2018} & Bräsher e Guimarães & 7 & $\begin{array}{l}\text { Introdução (3), Revisão de literatura (2) e } \\
\text { Resultados (2) }\end{array}$ \\
\hline & Linden e Bräsher & 6 & $\begin{array}{l}\text { Introdução (2), Revisão de literatura (2), } \\
\text { Metodologia (1) e Resultados (1) }\end{array}$ \\
\hline \multirow{3}{*}{2019} & Carvalho e Almeida & 8 & $\begin{array}{l}\text { Introdução (1), Revisão de literatura (4) e } \\
\text { Conclusão (3) }\end{array}$ \\
\hline & Oliveira e Martínez-Ávila & 12 & $\begin{array}{l}\text { Introdução (4), Revisão de literatura (4), } \\
\text { Metodologia (2) e Conclusão (2) }\end{array}$ \\
\hline & Sundström, Moraes e Albuquerque & 2 & Revisão de literatura (1) e Conclusão (1) \\
\hline Total & & 172 & \\
\hline
\end{tabular}

Tabela 3. Tratamento temático da informação no texto dos artigos.

Fonte: dados da pesquisa (2020)

Constata-se, ademais, certa variação no uso do termo "tratamento temático da informação" entre as várias seções do texto. Seu emprego se faz de forma a contextualizar, definir e explicitar seu conceito, tanto na introdução quanto na revisão de literatura. Nos resultados, a expressão insurge para dar voz aos comentários e constatações do estudo. Na conclusão, seu aparecimento é um meio de retomar o cerne da pesquisa e esclarecer o que foi alcançado nela.

Reforça-se, assim, o caráter desafiador do tratamento temático da informação (Sousa, 2013). Afinal, para além de sua distinção teórica e de sua abordagem individualizada do tratamento descritivo, requer integralização nominativa que permita reforçar seus procedimentos e superar intercorrências conceituais. Para tanto, há que se reconhecer sua nomeação distinta e seu emprego em pontos diversos em um mesmo texto, com diferentes finalidades.

Nos nove artigos com ocorrências da expressão TTI na metodologia — Guimarães e Sales; Dal'Evedove e Fujita; Sousa e Fujita; Rodrigues e Cervantes; Medeiros, Vital e Bräscher; Redigolo e Silva; Sales e Guimarães; Linden e Bräscher; e Oliveira e Martínez-Ávila - constata-se que o termo é empregado, de modo geral, apenas para reafirmar o objetivo da pesquisa, caracterizando os procedimentos realizados, não para designá-lo como um método da investigação.

Marcadamente, nos textos de Redigolo e Silva e de Sales e Guimarães, o termo é adotado na metodologia para explicitar as referências teóricas discutidas no assunto. Em Guimarães e Sales, Medeiros, Vital e Bräscher e, Oliveira e Martínez-Ávila, para caracterizar a população da pesquisa. 
Já no trabalho de Linden e Bräscher, o TTI faz parte do desenho metodológico. As autoras utilizam as correntes teóricas da área para comparar com a descrição de conteúdo nos instrumentos normativos arquivísticos. Esse estudo é, pois, o que mais se apropria do TTI para a instanciação metodológica. Ainda assim, o TTI não se caracteriza efetivamente como método em nenhum dos trabalhos.

Quanto às variantes designativas do TTI nos textos, constatam-se ocorrências significativas dos termos "descrição temática" e "representação temática". O primeiro insurge em 6 artigos, com um total de 10 ocorrências. O segundo aparece em 14 artigos, com um conjunto de 47 ocorrências.

Ainda, em algumas publicações, os termos abordagem temática, análise temática, dimensão temática, organização temática e vertente temática são utilizados, mas em menor número. De modo que, as variantes designativas mais comuns da expressão "tratamento temático da informação", são representação temática e, em menor grau, descrição temática.

\section{CONCLUSÃO}

O estudo buscou analisar a ocorrência da expressão "tratamento temático da informação" e de suas variantes designativas em artigos de periódicos brasileiros da Ciência da Informação, versados no tema, como forma de aclarar o assunto em sua perspectiva terminológica e perscrutar seu lastro teórico na literatura. O pressuposto de que a produção científica nacional sobre o TTI congrega distintas nomenclaturas foi parcialmente comprovado.

Constatou-se, pois, que as publicações sobre o assunto empregam o termo TTI de modo recorrente ao longo do texto, com destaque para a revisão de literatura, apesar de surgir também na introdução e nos resultados, em quantidade considerável. Tem-se, assim, indicativo de que uma teorização específica vem sendo construída em torno do tema, tecendo, inclusive, constatações analíticas sobre ele.

O tratamento temático da informação se estabelece, ainda, como designação padrão nas publicações nele versadas. Isso porque, no título, a expressão é sinalizada em pouco mais da metade das produções, em sua forma integral e nas formas variantes "tratamento temático" e "tratamento da informação".

Com relação às partes iniciais do artigo, que acompanham o título, destaca-se que a utilização do TTI também se mostra bastante expressiva. Quase que de forma concomitante no resumo e nas palavras-chave. Uma pequena quantidade de trabalhos não emprega o termo nessas duas instâncias textuais, ou ainda, o utiliza somente em um dos dois pontos.

Em alguma medida, portanto, há uma recorrência do termo TTI nos artigos que versam sobre ele, o que sinaliza para sua afirmação na literatura biblioteconômica. Contudo, as variantes designativas a partir das palavras "descrição" e "representação" também estão presentes, assim como outras formas sinonímicas, ainda que utilizadas em menor grau. Nessa via, tem-se um padrão nominativo como tratamento temático da informação nas produções científicas analisadas, mas também, um emprego robusto sobretudo da variante designativa representação temática.

Há que se ressaltar, então, a constante variação das formas empregadas para designação do TTI tanto no decorrer de um mesmo texto, em suas diversas partes constituintes, quanto entre as publicações, nas distintas formas expressas no título. Em termos teóricos, portanto, o tema percorre um caminho de certo modo ainda irregular, no que se refere à sua unicidade nominativa. Isso porque, na medida em que é substituído pelas variantes descrição e representação temática ou surge ora como tratamento da informação, em alguns pontos como tratamento temático e, em outros momentos como tratamento temático da informação, em sua forma completa, oscila nominalmente tanto quanto na afirmação da expressão na literatura, de modo contínuo.

Ainda assim, observa-se um conjunto de publicações sobre tratamento temático da informação na forma de artigos de periódicos, corpus esse que expõe a variação do termo, de forma intra e extratextual. Ainda assim, envida o reconhecimento da dimensão temática de organização, já que tem sido objeto de pesquisa e, em âmbito aplicado, pode viabilizar reflexões e revisão de procedimentos no decurso do trabalho de representação do assunto, pelo distinto teor conjecturado em tais produções científicas.

Por fim, é importante enfatizar que a diversidade terminológica pode ter motivos variados. A começar pelas correntes que sustentaram o desenvolvimento do TTI. Mas, ao mesmo tempo, a alternância nas palavras possibilita ao pesquisador diligenciar-se na deliberação conceitual do tema, pelo emprego de sinônimos que auxiliem em seu reconhecimento e compreensão. Razão pela qual a pesquisa demanda continuidade. Sugerem-se, então, estudos futuros dedicados a analisar se o uso do termo é destinado à conceituação e discussão, ou somente em abordagens dispersas e desguarnecidas de aprofundamento teórico no assunto.

Agradecimento: A Yasmin Pereira de Oliveira, pela formatação gráfica das figuras. 


\section{REFERÊNCIAS}

Albrechtsen, H. (1993). Subject analysis and indexing: from automated indexing to domain analysis. The Indexer, 18(4), 219-224. Recuperado de https://pdfs.semanticscholar.org/ d124/b3c48d681d2cd77f612ee2d9602850747e07.pdf

Araújo, C. A. Á. (2020). Por uma história intelectual da arquivologia, da biblioteconomia e da museologia desde uma perspectiva transversal. Information, 25(1), 4-29. Recuperado de https://informatio.fic.edu.uy/index.php/informatio/ article/view/251

Baptista, D. M. (1994). Do caos documentário à gerência da informação. Ciência da Informação,, 23(2), 239-248. Recuperado de https://repositorio.unb.br/handle/10482/ 1304

Bräscher, M., \& Guimarães, J. A. C. (2018). Tratamento temático da informação (tti): influência dos paradigmas físico, cognitivo e social em artigos de revisão de literatura no período de 1966-1995. Liinc em Revista, 14(2), 241258. Recuperado de http://revista.ibict.br/liinc/article/ view $/ 4347 / 3949$

Braz, M. I., \& de Carvalho, E. S. (2017). Práticas em tratamento temático da informação: interfaces de ensino e aprendizagem. Revista Brasileira de Biblioteconomia e Documentação, 13(esp.). Recuperado de https://rbbd.febab .org.br/rbbd/article/view/975/951

Café, L. M. A., \& Sales, R. (2010). Organização da informação: conceitos básicos e breve fundamentação teórica. In Passeios no bosque da informação: estudos sobre representação e organização da informação e do conhecimento. brasília df: Ibict (p. 115-129). Brasília: IBICT.

Catarino, M. E., Cervantes, B. M. N., \& Andrade, I. A. (2015). A representação temática no contexto da web semântica. Informação $\&$ Sociedade, 25(3), 105-116. Recuperado de https://periodicos.ufpb.br/ojs2/index.php/ies/ article/view/16242

Dal'Evedove, P. R. (2014). O tratamento temático da informação em abordagem sociocultural: diretrizes para definição de política de indexação em bibliotecas universitárias (Tese de doutorado, Universidade Estadual Paulista Júlio de Mesquita Filho, Brasil). Recuperado de https://repositorio.unesp.br/handle/11449/110385

Dal'Evedove, P. R., \& Fujita, M. S. L. (2013). Estudo sociocultural da comunidade discursiva do tratamento temático da informação em bibliotecas universitárias. Encontros Bibli: revista eletrônica de biblioteconomia e ciência da informação, 18(36), 23-50. Recuperado de https://periodicos.ufpb.br/ index.php/pbcib/article/view/18640

Danuello, J. C. (2007). Produção científica docente em tratamento temático da informação no brasil: uma abordagem métrica como subsídio para a análise do dominio (Dissertação de mestrado, Universidade Estadual Paulista Júlio de Mesquita Filho, São Paulo, Brasil). Recuperado de https://repositorio.unesp.br/handle/11449/95532

Gonçalves, A. L. (2008). Uso de resumos e palavras-chave em ciências sociais: uma avaliação. Encontros Bibli: revista eletrônica de biblioteconomia e ciência da informação, 13(26). Recuperado de https://periodicos.ufsc.br/ index.php/eb/article/view/1518-2924.2008v13n26p78

Gracioso, L. S., Martínez-Ávila, D., \& Simões, M. G. M. (2019). "tratamento temático da informação" na pesquisa brasileira em ciência da informação: percursos e relações. Scire, 25 (2), 23-24. Recuperado de https://www.ibersid.eu/ ojs/index.php/scire/article/view/4647/4239
Guimarâes, J. A., Ferreira, G. M., \& Freitas, M. F. M. (2011). Correntes teóricas do tratamento temático da informação: uma análise de domínio da presença da catalogação de assunto e da indexação nos congressos de isko-españa. In M. de los c. pérez pais, $83 \mathrm{~m}$. de los a. gonzález bonome (orgs.). 20 años del capítulo español de isko (p. 181-194). actas del X Congreso ISKO-España. Ferrol: Universidade da Coruña.

Guimarães, J. A. C. (2008). A dimensão teórica do tratamento temático da informação e suas interlocuções com o universo científico da international society for knowledge organization (isko). Revista Ibero-americana de Ciência da Informação, 1(1), 77-99. Recuperado de https:// periodicos.unb.br/index.php/RICI/article/view/940/815

Guimarães, J. A. C., \& Sales, R. d. (2010). Análise documental: concepções do universo acadêmico brasileiro em ciência da informação. DataGramaZeroRevista de Ciência da Informação, 11(1). Recuperado de https://web.archive.org/web/20160224181532/http:// www.dgz.org.br/fev10/Art_02.htm

Guinchat, C., \& Menou, M. (1994). Introdução geral às ciências e técnicas da informação e documentação. Brasília: IBICT. Recuperado de https://livroaberto.ibict.br/handle/ $1 / 1007$

Hider, P. (2020). Origins of the knowledge organization field. In Isko encyclopedia of knowledge organization. Recuperado de https://www.isko.org/cyclo/origins

Hjørland, B. (2012). Knowledge organization= information organization? In Categories, contexts and relations in knowledge organization: Proceedings of the twelfth international isko conference 6-9 august 2012 mysore, india (p. 206-211). Ergon Würzburg, Germany.

Hjørland, B. (2017). Subject (of documents). Knowledge Organization, 44(1), 55-64. Recuperado de https://www .isko.org/cyclo/subject

Lara, M. L. G. (2011). Conceitos de organização e representação do conhecimento na ótica das reflexões do grupo temma. Informação É Informação, 16(2), 92-121. Recuperado de http://www.uel.br/revistas/uel/index.php/informacao/ article/view/10391

Lunardelli, R. S. A. (2017). Mecanismos de distanciamento linguístico: a preservação da face na síntese documental. Perspectivas em Ciência da Informação, 22(1), 4-16. Recuperado de http://portaldeperiodicos.eci.ufmg.br/index.php/ pci/article/view/2761/1834

Oliveira, E. F. T., \& Gracio, M. C. C. (2011). Indicadores bibliométricos em ciência da informação: análise dos pesquisadores mais produtivos no tema estudos métricos na base Scopus. Perspectivas em Ciência da Informação, 16(4), 16-28. Recuperado de https://www.scielo.br/scielo .php?script=sci_arttext\&pid $=$ S1413-99362017000100004

Oliveira, L. P., Grácio, M. C. C., \& Martínez-Ávila, D. (2020). Instrumentos, processos e produtos do tratamento temático da informação: um estudo nos anais da iskobrasil (2012-2019). Scire: representación y organización del conocimiento, 26(1), 47-56. Recuperado de https:// www.ibersid.eu/ojs/index.php/scire/article/view/4681

Oliveira, L. P., \& Martínez-Ávila, D. (2019). Tratamento temático da informação: análise sobre abordagens e enfoques em artigos científicos da área de ciência da informação. Informação em Pauta, 4(2), 83-100. Recuperado de http://www.periodicos.ufc.br/informacaoempauta/ article/view/42654 
Olson, H. A. (2002). Naming is power. In The power to name (p. 1-15). Dordrecht: Springer.

Pando, D. A., \& Guimarães, J. A. C. (2006). O profissional da informação e as atividades de organização da informação/conhecimento. Interatividade, 1(2). Recuperado de https://issuu.com/mariana_maia/docs/002_ci

Rabelo, C. R. O., \& Bentes, P. V. (2019). Tendências nos estudos de representação temática da informação: uma revisão integrativa dos artigos científicos indexados na brapci. Em Questão, 25(2), 66-88. Recuperado de https://seer.ufrgs.br/EmQuestao/article/view/82314

Reis, F. C. M. (2015). A análise documentária na representação do conhecimento: estudo bibliométrico da produção científica (Dissertação de mestrado, Universidade Federal de Minas Gerais, MG, Brasil). Recuperado de https://repositorio.ufmg.br/bitstream/1843/BUBD -A35GRS/1/disserta o final.pdf

Robredo, J. (2004). Organização dos documentos ou organização da informação: uma questão de escolha. Data Grama Zero, 5(1). Recuperado de https://brapci.inf.br/index.php/ res/download/44798

Robredo, J., \& Vilan Filho, J. L. (2010). Metrias da informação: história e tendências. In Passeios pelo bosque da informação: estudos sobre representação e organização da informação e do conhecimento (p. 184-258). Brasília: IBICT.

Silva, N. S., \& Silva, M. B. (2012). A contribuição da organização da informação na responsabilidade social da biblioteca da ambep. Biblionline, 8 (esp), 214-230. Recuperado de https://periodicos.ufpb.br/ojs2/index.php/biblio/ article/view/14206/8111

Sousa, B. P. (2013). Representação temática da informação documentária e sua contextualização em biblioteca. Revista brasileira de biblioteconomia e documentação, 9(2), 132146. Recuperado de https://rbbd.febab.org.br/rbbd/article/ view $/ 249$

Sousa, B. P., \& Fujita, M. S. L. (2013). A classificação bibliográfica no contexto do tratamento temático da informação: um estudo com o protocolo verbal individual em bibliotecas do instituto federal de educação, ciência e tecnologia (if' s). Revista ACB: Biblioteconomia em Santa Catarina, 796-813. Recuperado de https://revista.acbsc.org.br/racb/ article/view/868

Souza, R. F. (2007). Organização do conhecimento. In Para entender a ciência da informação (p. 103-123). Salvador: EDUFBA.

Vieira, A. P. F., Oliveira, L. P., \& Cunha, T. M. (2017). Incursões sobre o tratamento temático da informação: estudo da política de indexação em bibliotecas universitárias goianas. Informação em Pauta, 2(1), 28-49. Recuperado de http://www.periodicos.ufc.br/informacaoempauta/ article/view/6542

Vieira, K. R., Bräscher, M., Silva, E. C. L., \& Karpinski, C. (2020). A escola de chicago e a dimensão temática da informação. Informação ES Informação, 25(1), 211-228. Recuperado de http://www.uel.br/revistas/uel/index.php/ informacao/article/view/38817

Whittaker, J. (1989). Creativity and conformity in science: Titles, keywords and co-word analysis. Social Studies of Science, 19(3), 473-496. Recuperado de https://www.jstor .org/stable/285083?seq=1
Como citar este artigo (APA):

Oliveira, L. P., Grácio, M. C. C. \& Martínez-Ávila, D. (2020). A expressão "Tratamento Temático da Informação" em artigos de periódicos nacionais: análise da ocorrência e de suas variantes designativas. AtoZ: novas práticas em informação e conhecimento, 9(2), 44 - 56. Recuperado de: http://dx.doi.org/10.5380/ atoz.v9i2.75008 